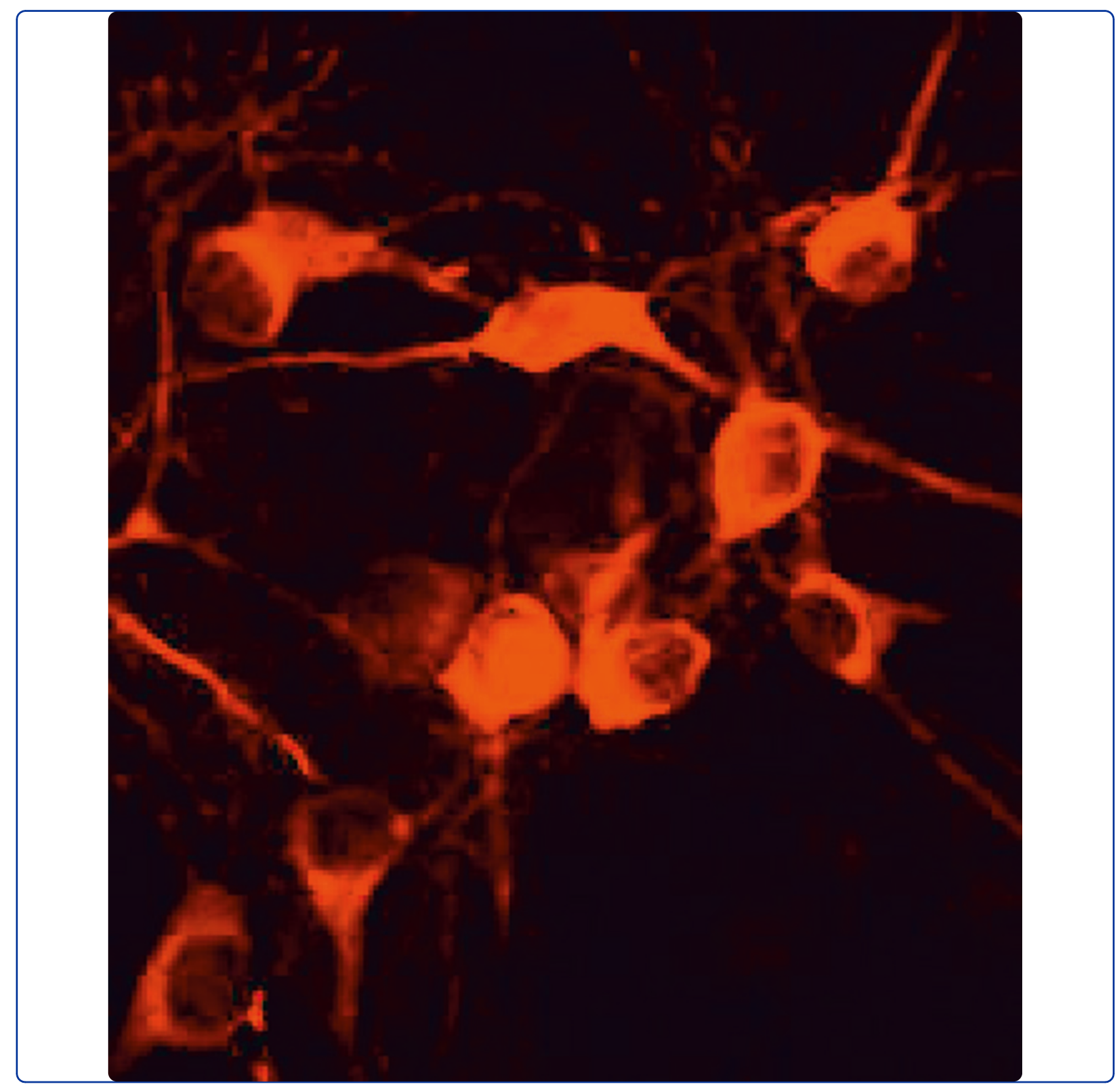

\title{
WIdS but not Nmnat1 protects dopaminergic neurites from MPP+ neurotoxicity
}

Antenor-Dorsey and O'Malley 


\title{
WId $d^{S}$ but not Nmnat1 protects dopaminergic neurites from $\mathrm{MPP}^{+}$neurotoxicity
}

\author{
Jo Ann V Antenor-Dorsey and Karen L O'Malley
}

\begin{abstract}
Background: The WId ${ }^{S}$ mouse mutant ("Wallerian degeneration-slow") delays axonal degeneration in a variety of disorders including in vivo models of Parkinson's disease. The mechanisms underlying WId ${ }^{S}$-mediated axonal protection are unclear, although many studies have attributed $\mathrm{WId}^{S}$ neuroprotection to the $\mathrm{NAD}^{+}$-synthesizing Nmnat1 portion of the fusion protein. Here, we used dissociated dopaminergic cultures to test the hypothesis that catalytically active Nmnat1 protects dopaminergic neurons from toxin-mediated axonal injury.

Results: Using mutant mice and lentiviral transduction of dopaminergic neurons, the present findings demonstrate that $W_{1} d^{S}$ but not Nmnat1, Nmnat3, or cytoplasmically-targeted Nmnat1 protects dopamine axons from the parkinsonian mimetic $\mathrm{N}$-methyl-4-phenylpyridinium $\left(\mathrm{MPP}^{+}\right)$. Moreover, $\mathrm{NAD}^{+}$synthesis is not required since enzymatically-inactive $W_{I}^{S}$ still protects. In addition, NAD ${ }^{+}$by itself is axonally protective and together with WId ${ }^{S}$ is additive in the $\mathrm{MPP}^{+}$model.
\end{abstract}

Conclusions: Our data suggest that $\mathrm{NAD}^{+}$and $W / d^{S}$ act through separate and possibly parallel mechanisms to protect dopamine axons. As $\mathrm{MPP}^{+}$is thought to impair mitochondrial function, these results suggest that WId ${ }^{S}$ might be involved in preserving mitochondrial health or maintaining cellular metabolism.

Keywords: WId ${ }^{S}$, Nmnat1, Parkinson?'?s disease, $\mathrm{MPP}^{+}$, dopaminergic neurons, axonal degeneration

\section{Background}

Parkinson's disease (PD) is the second most common neurodegenerative disorder in the U.S., affecting 1-2\% of people over the age of 55 . Characterized by loss of dopaminergic neurons in the substantia nigra (SN) [1,2], the cardinal motor symptoms of PD include resting tremor, bradykinesia, rigidity, and abnormal gait $[3,4]$. Another characteristic of PD is its late onset and progressive nature. Symptoms appear after $50-70 \%[5,6]$ of striatal dopamine has been depleted and $30-50 \%[7,8]$ of the nigral dopaminergic cells have died. Such studies suggest that the extent of striatal dopamine depletion is better correlated with the severity of PD symptoms than the loss of dopaminergic neurons in the SN [7].

Data from PD-linked genetic mutations also support the notion that axonal pathology and/or dysfunction occurs prior to the loss of dopaminergic cell bodies. For example, $\alpha$-synuclein pathology is seen in neurites

\footnotetext{
* Correspondence: omalleyk@wustledu

* Correspondence: omalleyk@wustl.edu
Department of Anatomy and Neurobiology, Washington University School of Medicine, Saint Louis, MO, 63110, USA
}

(c) 2012 Antenor-Dorsey and O'Malley; licensee BioMed Central Ltd. This is an Open Access article distributed under the terms of the Creative Commons Attribution License (http://creativecommons.org/licenses/by/2.0), which permits unrestricted use, distribution, and reproduction in any medium, provided the original work is properly cited. a-synuclein mutants accumulate in the cell soma when overexpressed in cortical neurons, suggesting impaired axonal transport as well [10]. Moreover, transgenic models expressing the PD-linked mutant gene leucine rich repeat kinase 2 (LRRK2) also exhibit pronounced axonal loss and pathology prior to cell body loss [11]. In addition, genetic mutations in other PD-linked genes such as Parkin, an E3 ligase [12], and PINK1 (PTENinduced putative kinase 1 protein) a mitochondrially-targeted kinase, also alter axonal transport $[13,14]$. Collectively, these findings have led to the idea that nigral neurons degenerate through a "dying back" axonopathy where degeneration starts in the distal axon and proceeds over time towards the cell body.

Environmental toxins known to mimic PD such as rotenone and $\mathrm{MPP}^{+}$also disrupt axonal function. These factors not only inhibit mitochondrial Complex I activity, but also de-polymerize microtubules leading to axon fragmentation and decreased synaptic function [15-17]. Moreover, $\mathrm{MPP}^{+}$can directly inhibit axon transport in the squid axoplasm [18] and DA neurons [19]. Thus, 
results from $\mathrm{PD}$-associated environmental and genetic factors support an early, critical role for axonal impairment in PD.

Recent data suggest that the Wallerian degeneration slow fusion protein $\left(W l d^{S}\right)$ can delay axonal degeneration about 10 -fold from a wide variety of genetic and toxininducing stimuli in the peripheral nervous system [20]. $W l d^{S}$ also blocks axon degeneration in several central nervous system (CNS) models of degeneration including animal models of PD $[21,22]$. For example, we previously found that $W l d^{S}$ rescues $85 \%$ of dopaminergic axons for at least 7 days post MPTP treatment in vivo [23]. Because no other mutation or drug protects axons as robustly as $W l d^{S}$, understanding how the $W l d^{S}$ fusion protein is able to prevent axon degeneration is the first step towards defining an intervention that would leave axons intact.

$W l d^{S}$ is a chimeric protein composed of the first 70 amino acids of the ubiquitination factor E4b (Ube4b) followed by an 18-amino acid linker region and then the entire coding sequence for nicotinamide mononucleotide adenylyltransferase (Nmnat1), a nicotinamide adenine dinucleotide $\left(\mathrm{NAD}^{+}\right)$synthesizing enzyme $[24,25]$. Most studies suggest that catalytically active Nmnat1 is necessary for axonal protection [26,27], hence, exogenous addition of $\mathrm{NAD}^{+}$has been reported to delay Wallerian degeneration in response to axotomy in dorsal root ganglion (DRG) cells [28]. In Drosophila, however, the picture is more complex in that Avery et al. [29], showed that Nmnat enzymatic activity is required following axotomy whereas Zhai et al. [30] found that Nmnat does not need its catalytic domain to protect axons. In this model [30], as well as in a new study demonstrating that Nmnat also protects dendrites [31], Nmnat exhibits a separate chaperone-like activity which protects axons and dendrites [30,32].

Inasmuch as most studies have been done in peripheral model systems and because we have previously shown that $W l d^{S}$ protects dopaminergic terminal fields from MPTP in vivo, we used a dissociated midbrain culture system to determine the mechanism of $\mathrm{Wld}^{S}$ mediated neurite protection in dopamine neurons. Here, we show that, regardless of its enzymatic activity, the entire $W l d^{S}$ sequence is needed for the $W l d^{S}$, neuroprotective phenotype in dopaminergic neurons. Our data also illustrate that $\mathrm{NAD}^{+}$has a neuroprotective effect that is different from $W l d^{S}$-mediated protection.

\section{Results}

\section{WId ${ }^{S}$ protects cell bodies and neurites from MPP}

Previously we have shown that dopaminergic terminal fields but not cell bodies of $W l d^{S}$ mice are protected against MPTP injury [23]. To confirm and extend these observations in a more tractable system, we utilized dissociated cultures of midbrain neurons in which $1-5 \%$ of the total cells plated are dopaminergic [33]. Results show that cultures from $W l d^{S}$ mice exhibited significant protection of neurites not seen in wild type cultures after $\mathrm{MPP}^{+}$treatment (Figure 1A, C). Moreover, dopaminergic cell death from $\mathrm{MPP}^{+}$treatment was also attenuated in $W^{S} l d^{S}$ cultures, unlike those seen in vivo (Figure 1A, B). Thus $W l d^{S}$ can effectively protect neurites (dendrites and axons) as well as cell bodies from known PD mimetics in vitro.

\section{Cytoplasmic WId $^{S}$ protects cell bodies and neurites against $\mathrm{MPP}^{+}$}

Recent studies have reported that the localization of Wld $d^{S}$ influences its neuroprotective effect. Babetto et. al.

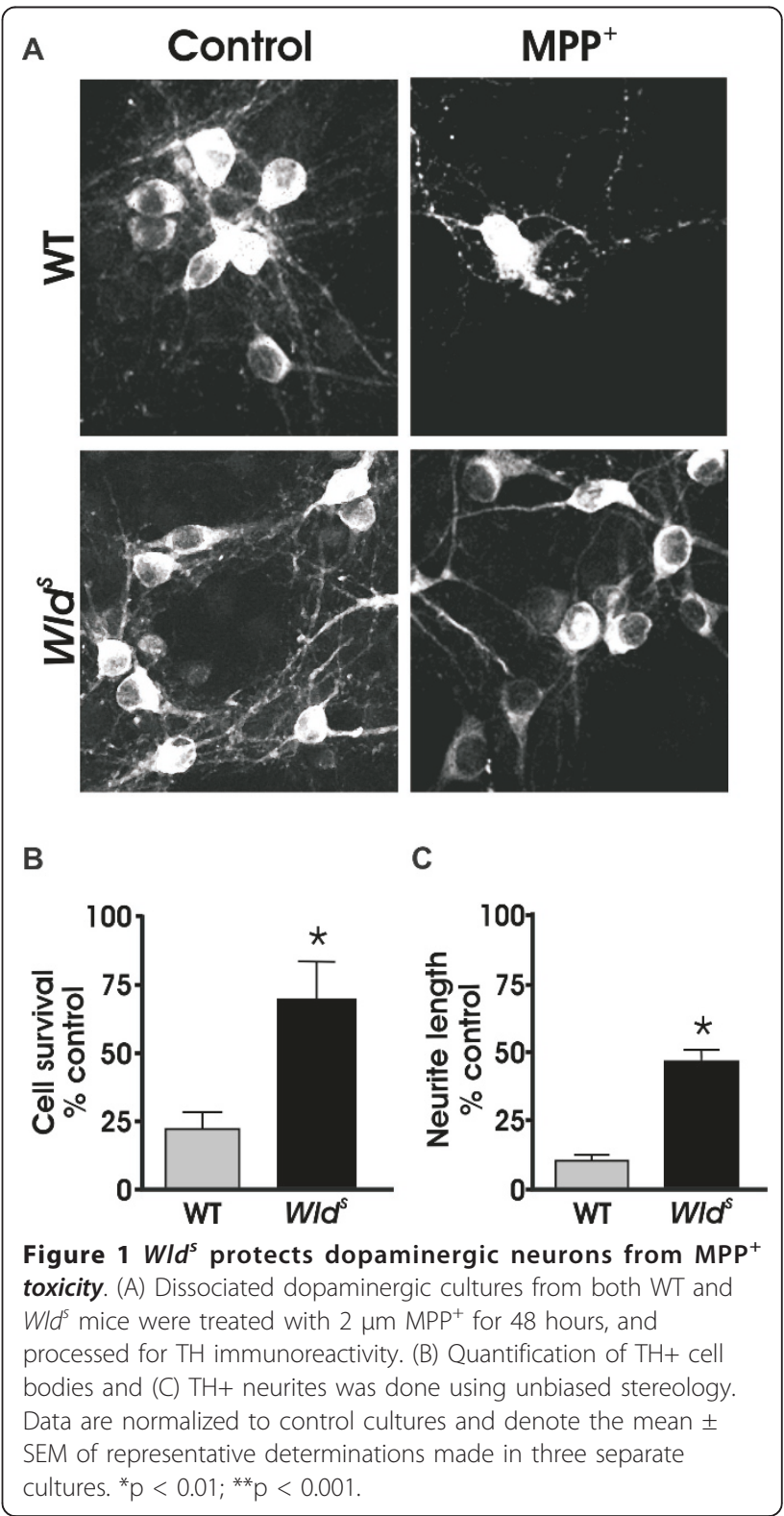


have reported that a cytoplasmic version of the $W l d^{S}$ protein $\left(\right.$ cyto $\mathrm{Wld} \mathrm{d}^{S}$ ) confers a higher level of protection than the native form of $W l d^{S}$ [34]. In addition, Sasaki et. al. have reported that cytoplasmic Nmnat1 (cyto Nmnat1) and Nmnat3, which is primarily localized in the mitochondria, also confer a higher level of protection than Nmnat1 $[35,36]$. To test whether cytoplasmic localization of $W l d^{S}$ rescued or changed the level of protection seen with nuclear $W l d^{S}$, primary dopaminergic neurons were prepared from wild type and cyto $\mathrm{Wld}^{S}$ mice, treated with $\mathrm{MPP}^{+}$, and analyzed as described. Results show that cyto $W l d^{S}$ mice exhibited a similar level of protection of dopaminergic cell bodies and neurites as seen in $W l d^{S}$ mice (Figure 2). Therefore, as reported for peripheral model systems and certain CNS paradigms [37], redirecting most of $\mathrm{Wld}^{\mathrm{S}}$ from the nucleus to the cytoplasm protects processes equally well.

\section{Nmnat1 does not protect against $\mathrm{MPP}^{+}$toxicity}

Many studies, especially in peripheral model systems, have shown that Nmnat1 can at least partially mimic the effects of $W l d^{S}[26,27]$. To determine whether this is true in dopaminergic neurons, we transduced primary midbrain cultures from wild type animals with either GFP, Nmnat1, the 70 amino acid fragment of Ube4b encoded within the $W l d^{S}$ gene, or the entire $W l d^{S}$ coding region using lentiviral vectors expressing GFP [27] (Figure 3). We also tested the effects of Nmnat3, cytoplasmic Nmnat1, and enzymatically inactive Nmnat1 (Nmnat1 (W170A)) [28,38] (Figure 3D, E and Additional File 1 Figure S1C, D). Immunofluorescence and western blotting was done to confirm that transductions led to similar expression levels in dissociated cultures (Figure 3B, C, Additional File 1 Figure S1B, D-E). Despite equivalent levels of transgene expression, only neurites transduced with the entire coding sequence of $W l d^{S}$ were protected from $\mathrm{MPP}^{+}$injury (Figure 3D, E).

Because many studies have suggested that Nmnat and in particular cyto Nmnat or axonally targeted Nmnat can be as effective as $W l d^{S}$ in protecting axons from mechanical or toxic insults, we used DRG cultures as a positive control $[34,39]$. Consistent with those studies, both $\mathrm{Wld}^{S}$ and cyto Nmnat rescued DRG neurites from the neurotoxin, vincristine, whereas the GFP-only and inactive $W l d^{S}$ virus did not (Figure 4). Taken together, these data confirm previous results showing that cyto Nmnat is necessary and sufficient to save DRG neurites. In contrast, only $W l d^{S}$ but not cyto Nmnat, Nmnat1, or Nmnat3 was able to protect dopaminergic neurons from the neurotoxic effects of $\mathrm{MPP}^{+}$.

\section{Inactive $W I d^{S}$ protects cell bodies and neurites against MPP $^{+}$}

To corroborate the hypothesis that Nmnat1 does not protect dopaminergic neurons from $\mathrm{MPP}^{+}$, we transduced dissociated primary midbrain cultures with enzymatically inactive $W l d^{S}$ (W258A; [27]). In contrast to our own results in DRG cultures (Figure 4) as well as results published by others using this same construct [27], the inactive $W l d^{S}$ plasmid was as effective as NAD ${ }^{+}$-synthesizing $\mathrm{Wld}^{S}$ animals in protecting dopaminergic cell bodies and neurites against $\mathrm{MPP}^{+}$injury (Figure 5). Therefore, the entire $W l d^{S}$ chimeric protein, but not its $\mathrm{NAD}^{+}$-synthesizing activity, is required for neuroprotection of dopaminergic neurons.

\section{$N A D^{+}$protects cell bodies and neurites against $\mathrm{MPP}^{+}$}

Previous studies have shown that $\mathrm{NAD}^{+}$itself can be neuroprotective [27]. Although Nmnat1 by itself did not recapitulate the neuroprotective effect of $W l d^{S}$ on dopaminergic neurons, we tested whether $\mathrm{NAD}^{+}$or one of its precursors (Figure 6A) rescued cell bodies or neurites from $\mathrm{MPP}^{+}$treatment. Therefore, dissociated dopaminergic wild type cultures were pretreated with either 1 $\mathrm{mM}$ of $\mathrm{NAD}^{+}$, nicotinamide mononucleotide (NMN), or nicotinic acid mononucleotide (NaMN) 24 hours before $\mathrm{MPP}^{+}$treatment. Both $\mathrm{NAD}^{+}$and NMN but not NaMN protected cell bodies and neurites against $\mathrm{MPP}^{+}$toxicity (Figure 6B, C). These findings together with the results showing that catalytically-inactive $W_{l d}$ was able to protect dopamine neurons (Figure 5) but catalytically active Nmnat did not (Figure 3F) suggest that different pathways are being invoked in response to $\mathrm{MPP}^{+}$toxicity.

\section{Sirt1 is not responsible for the NAD-mediated protection of cell bodies and neurites against MPP ${ }^{+}$}

Previous studies in DRG neurons have attributed the protective phenotype of $W_{l} d^{S}$ to its action on the Nmnat1-NAD ${ }^{+}$-Sirt1 pathway [27]. To test the involvement of Sirt1, we prepared dissociated dopaminergic cultures from Sirt1 knockout mice. Following 24 hour pretreatment with $1 \mathrm{mM} \mathrm{NAD}^{+}$or vehicle control, cultures were exposed to $\mathrm{MPP}^{+}$. Consistent with the notion that $\mathrm{NAD}^{+}$is not acting through Sirt1 but rather through a different mechanism, NAD ${ }^{+}$protected cell bodies and neurites in Sirt1 knockout cultures from $\mathrm{MPP}^{+}$toxicity (Figure 7 ).

\section{$N A D^{+}$and $W I d^{S}$ effects are additive}

The data described above suggest that $W l d^{S}$ is acting through a separate possibly parallel pathway from that of $\mathrm{NAD}^{+}$in dopaminergic neurons. If so, then adding $\mathrm{NAD}^{+}$to $\mathrm{Wld}^{S}$ cultures will enhance the neuroprotective phenotype of $W_{l} d^{S}$. To see whether the NAD ${ }^{+}$ effect overlapped with $W l d^{S}$ or was additive, dissociated dopaminergic cultures were prepared from wild type and $W l d^{S}$ mice and pre-treated with and without $\mathrm{NAD}^{+}$ as previously described. Both $\mathrm{NAD}^{+}$and $\mathrm{Wld}^{S}$ alone exhibited similar levels of cell body and neurite 


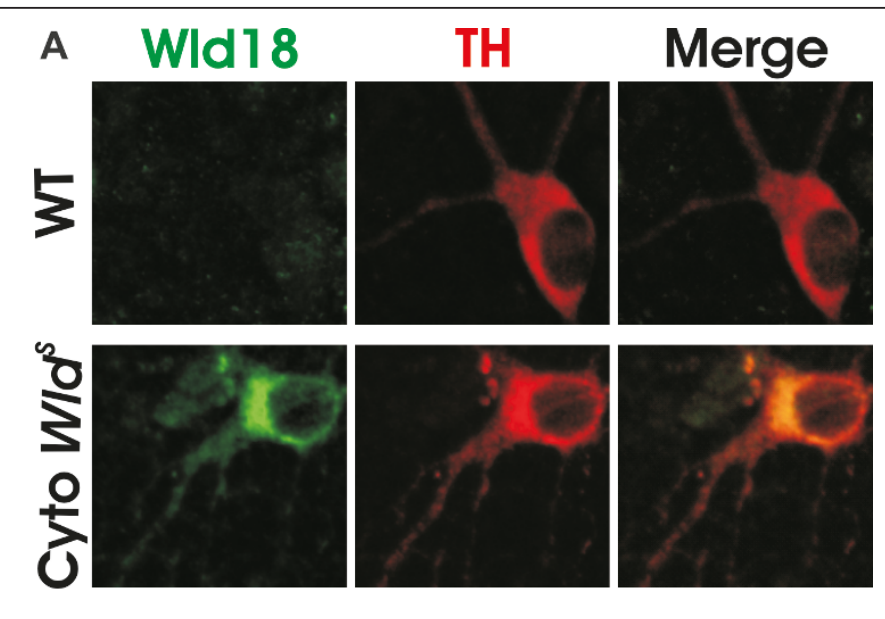

B
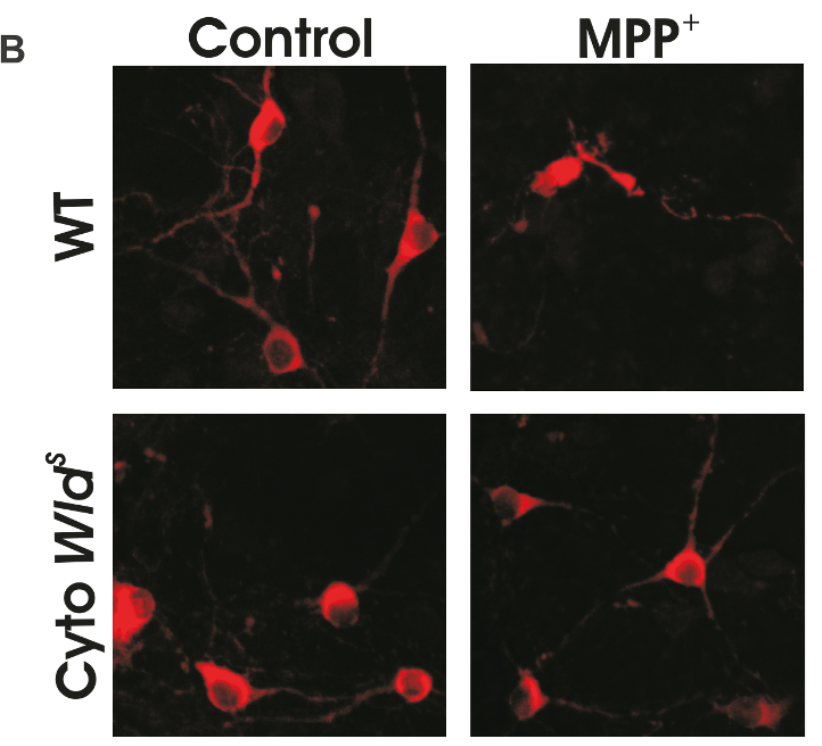

C

D
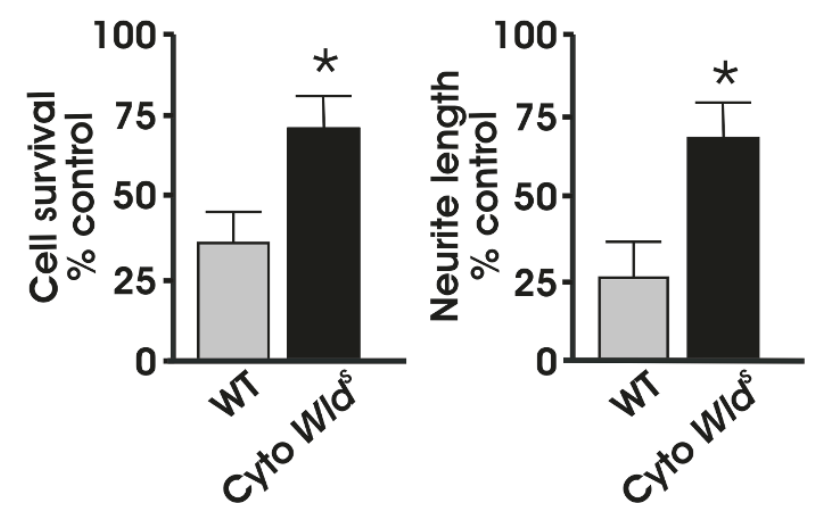

Figure 2 Cytoplasmic WId $d^{5}$ protects dopaminergic neurons from MPP ${ }^{+}$toxicity. (A) Dissociated dopaminergic cultures from both WT and cyto WId $d^{5}$ mice were co-stained with TH and WId antibodies to confirm the subcellular localization of WId $d^{5}$. (B) Cultures were treated with $2 \mu \mathrm{m}$ $\mathrm{MPP}^{+}$for 48 hours prior to fixing and staining. (C) Quantification of TH+ cell bodies and (D) TH+ neurites shows that cytoplasmic WId ${ }^{S}$ protected both cell bodies and neurites against MPP ${ }^{+}$. Data are normalized to control cultures and denote the mean \pm SEM of representative determinations made in three separate cultures. ${ }^{*} p<0.05$. 

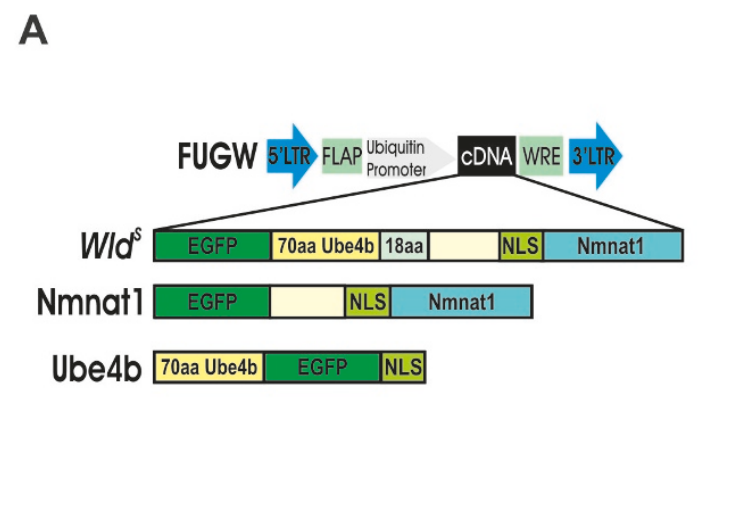

B
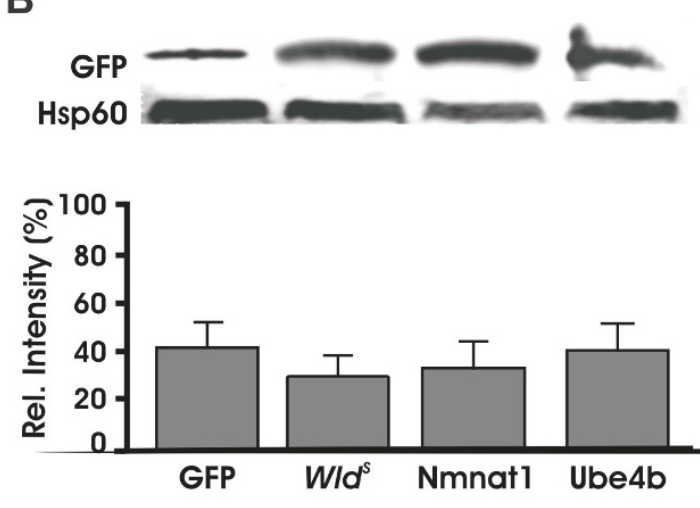

D

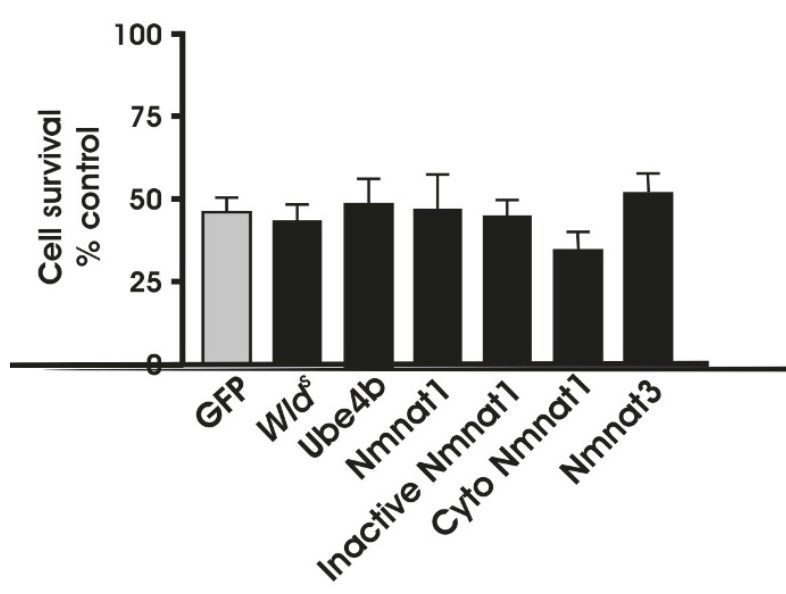

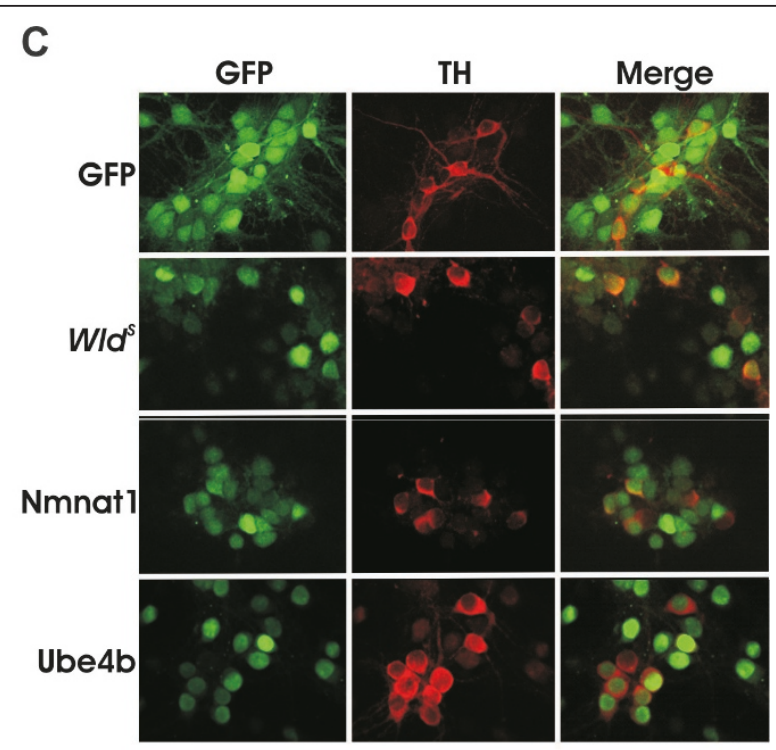

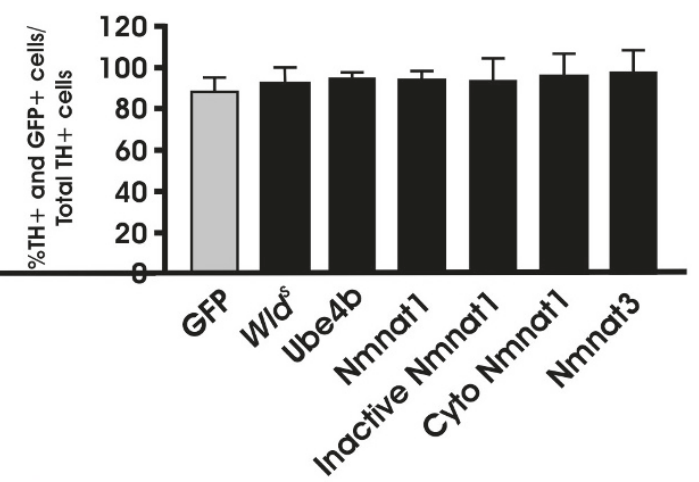

E

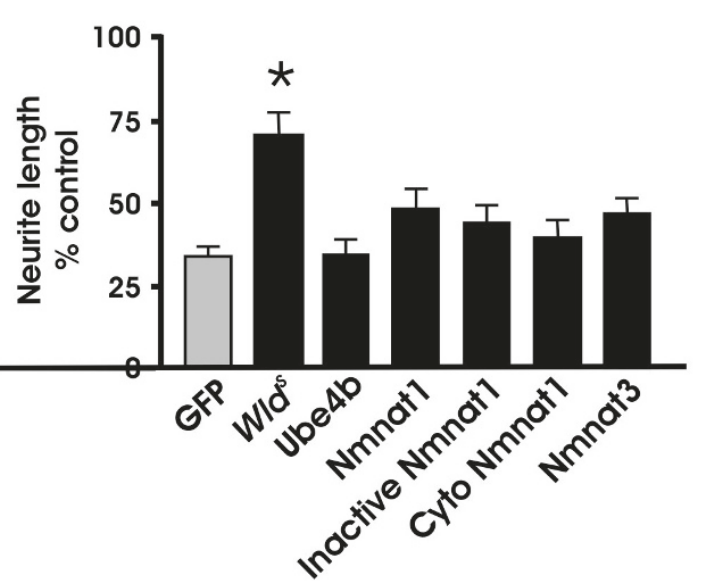

Figure 3 Nmnat by itself does not protect dopaminergic neurons from MPP $^{+}$toxicity. (A) Diagram of the lentiviral constructs used to transduce WT dissociated dopaminergic neurons. (B) Western blot of cell lysates from transduced primary midbrain cultures illustrates that all the transduced transgenes exhibit similar levels of expression. (C) Similar transduction efficiencies of the different lentiviruses were confirmed by quantifying the number of TH+ and GFP+ cells following transduction of dopaminergic cultures. (D) Quantification of TH+ cell bodies and (E) TH + neurites show that only $W{ }^{S} d^{S}$-transduced cultures protected neurites against $\mathrm{MPP}^{+}$. Data are normalized to control cultures and denote the mean \pm SEM of representative determinations made in three separate cultures. ${ }^{*} p<0.001$. 

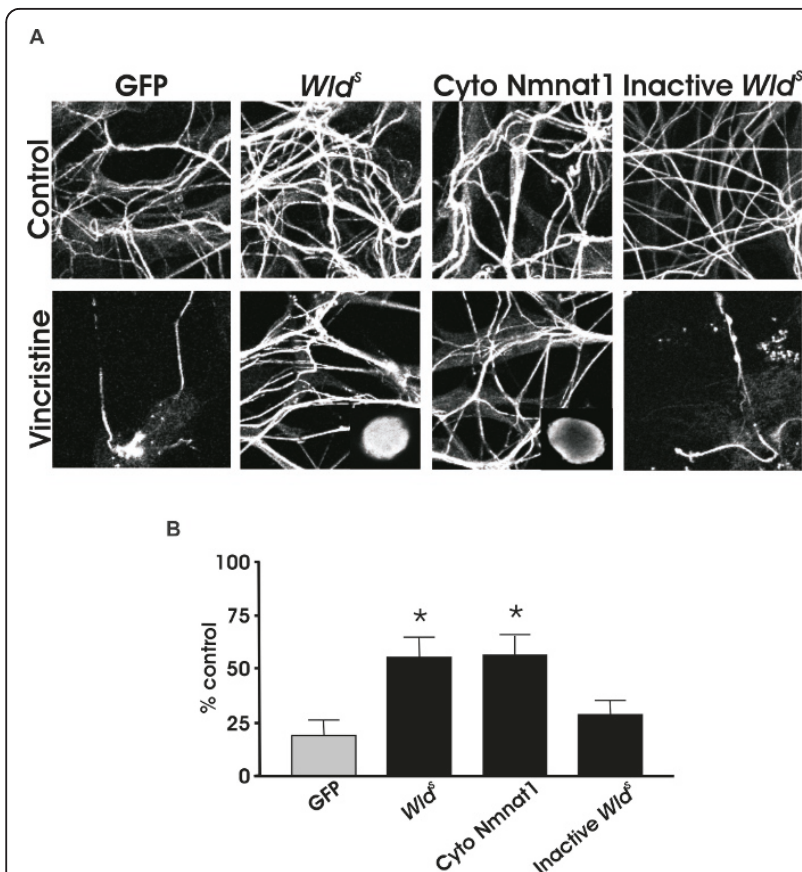

Figure $4 W^{W} d^{5}$ and cytoplasmic Nmnat1 protect DRG axons from vincristine toxicity. (A) DRG cultures from E14 mice transduced with GFP, WId , cyto Nmnat1, or inactive WId were processed for acetylated tubulin immunoreactivity 24 hours after vincristine treatment. Inserts in bottom middle panels show 40x images of DRG cell bodies transduced with WId ${ }^{5}$ and cytoplasmic Nmnat1, respectively, to illustrate no overt nuclear enrichment of Nmnat1. (B) Quantification of neurites shows that both WId and cyto Nmnat1 protects DRG neurites from vincristine toxicity. Data are normalized to control cultures and denote the mean \pm SEM of representative determinations made in three separate cultures. ${ }^{*} p<$ 0.05

protection (Figure 8 ). However, $\mathrm{NAD}^{+}$together with $W l d^{S}$ generated significantly higher levels of protection suggesting this is an additive process (Figure 8). To test whether these effects were maximal, additional cultures were treated with $5 \mathrm{mM} \mathrm{NAD}^{+}$; no significant differences in neuroprotection were observed when compared with the lower dose of $1 \mathrm{mM} \mathrm{NAD}^{+}$(Figure 8D). These findings demonstrate that $\mathrm{NAD}^{+}$and $\mathrm{Wld}^{S}$ are additive in the $\mathrm{MPP}^{+}$model suggesting that they are acting through separate and possibly parallel neuroprotective mechanisms.

\section{Discussion}

The mechanism(s) by which $W l d^{S}$ protects axons is still unclear. Peripheral model studies underscore the role of Nmnat and its product, $\mathrm{NAD}^{+}$, in protecting axons from various injuries whereas few central nervous system studies have been done. Using cellular, molecular and pharmacological tools, the present findings show that the chimeric $W l d^{S}$ gene product plays a critical role in

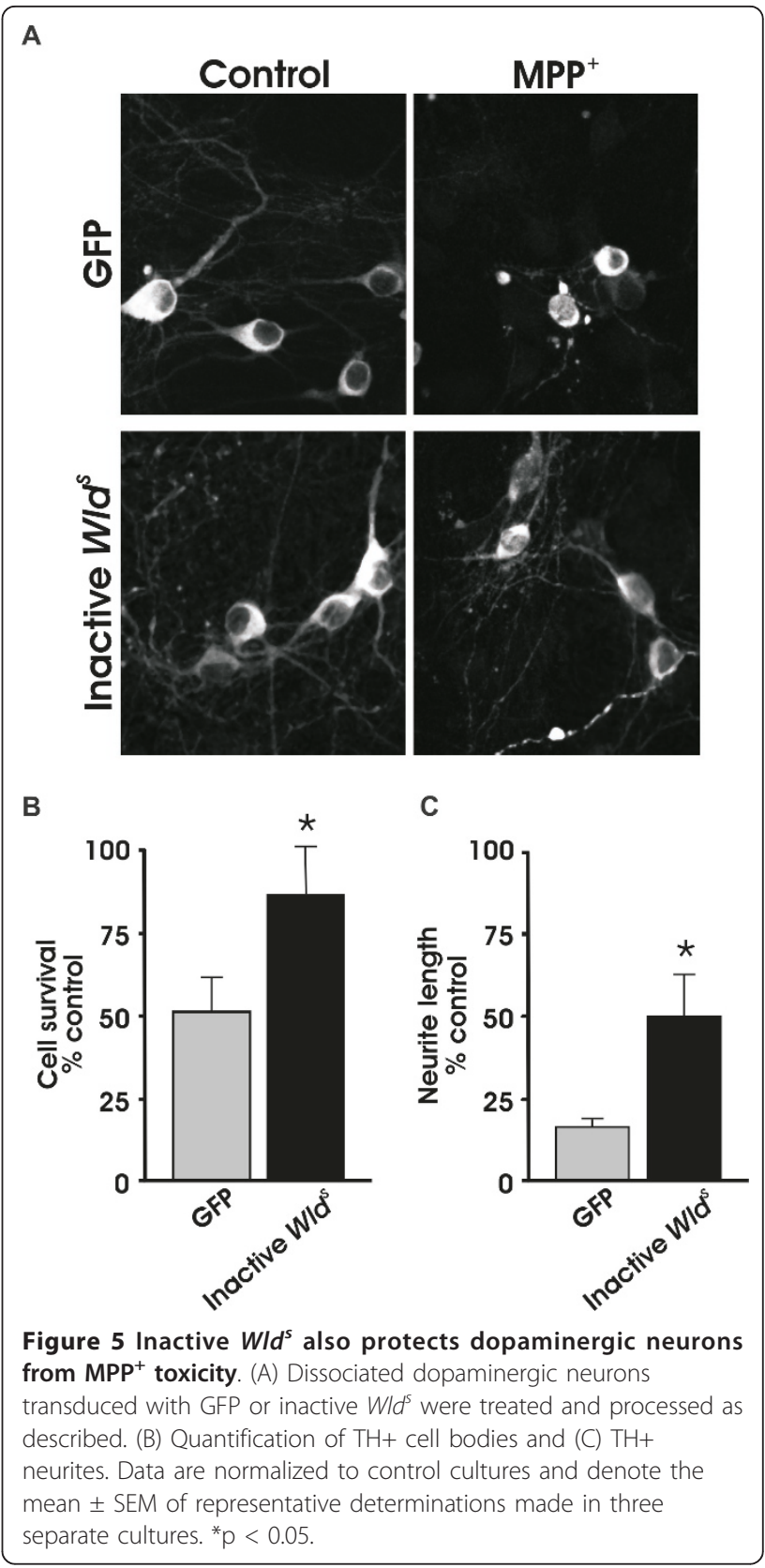

protecting dopaminergic processes, one not dependent upon Nmnat activity. Specifically, neither Nmnat, cytoplasmically-targeted Nmnat, nor Nmnat 3 were able to prevent toxicity associated with the dopaminergic toxin $\mathrm{MPP}^{+}$whereas, akin to previous reports [27,28], cyto Nmnat protected DRG axons from known axonal toxins. In contrast, $W l d^{S}$, cytoplasmically-expressed $W l d^{S}$, and $W l d^{S}$ with an inactive Nmnat domain, all significantly protected dopaminergic neurites from toxin-mediated loss. Despite the inability of Nmnat to protect dopamine processes, $\mathrm{NAD}^{+}$and its precursor, Nmn, were neuroprotective. As $W l d^{S}$ and $\mathrm{NAD}^{+}$were additive in this model 


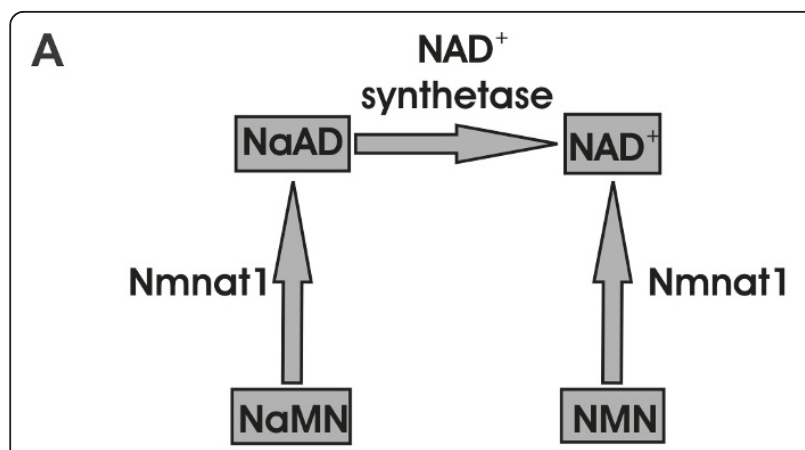

B

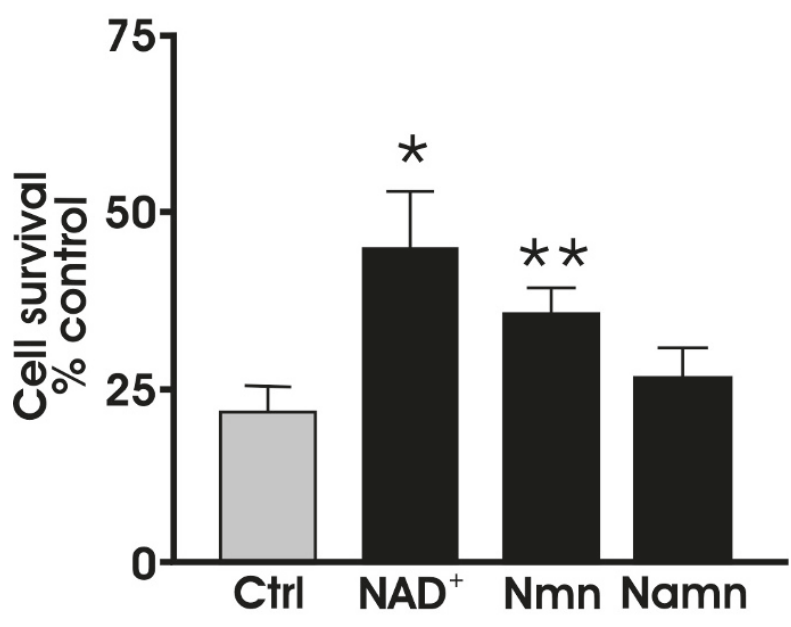

C

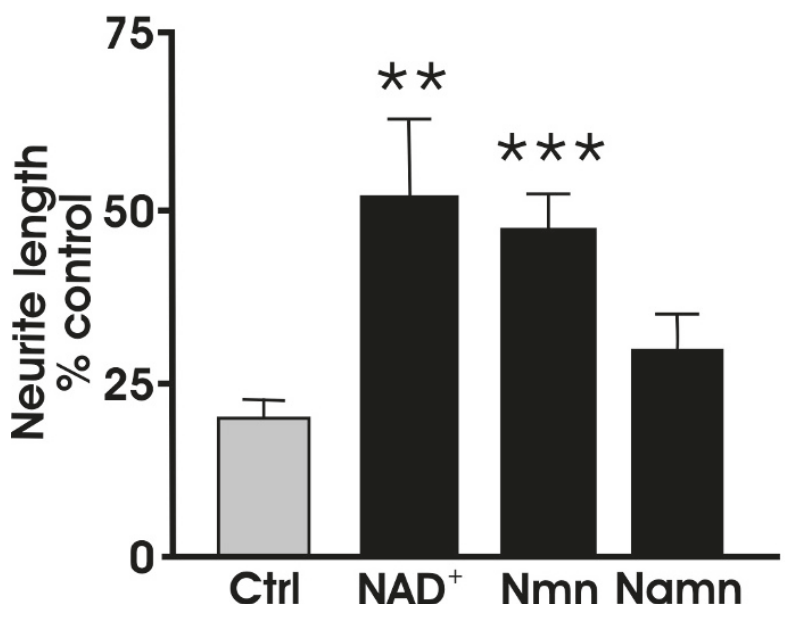

Figure $6 \mathrm{NAD}^{+}$protects dopaminergic cells and neurites from MPP $^{+}$toxicity. (A) NAD ${ }^{+}$biosynthetic pathway [75]. (B) Dissociated WT dopaminergic cultures were pretreated with $\mathrm{NAD}^{+}, \mathrm{Nmn}$, or Namn 24 hours before addition of $2 \mu \mathrm{m} \mathrm{MPP}$. Quantification of $\mathrm{TH}+$ cell bodies and (C) TH+ neurites show that $\mathrm{NAD}^{+}$and Nmn, but not Namn, protected cells and neurites from $\mathrm{MPP}^{+}$. Data are normalized to control cultures and denote the mean \pm SEM of representative determinations made in three separate cultures. ${ }^{*} p<0.05,{ }^{* *} p, 0.01,{ }^{* * *} p<0.001$.

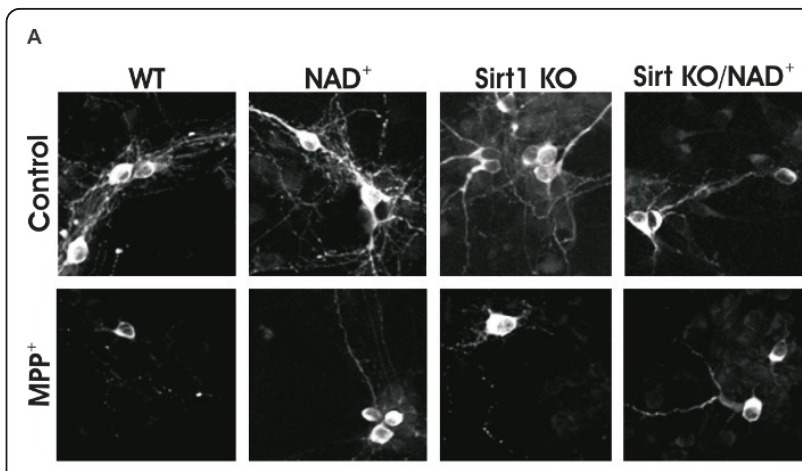

B

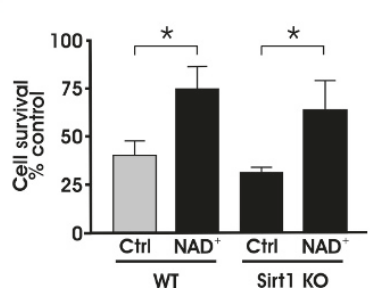

c

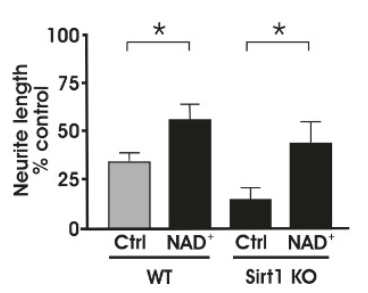

Figure $7 \mathrm{NAD}^{+}$does not protect dopaminergic neurons through the Sirt1 pathway. (A) Dissociated midbrain cultures from both $\mathrm{WT}$ and Sirt1 $\mathrm{KO}$ mice were pretreated with $\mathrm{NAD}^{+} 24$ hours before addition of $2 \mu \mathrm{m} \mathrm{MPP}{ }^{+}$. (B) Quantification of $\mathrm{TH}+$ cell bodies and $(\mathrm{C}) \mathrm{TH}+$ neurites show that $\mathrm{NAD}^{+}$protects cells and neurites from $\mathrm{MPP}^{+}$in both WT and Sirt1 KO cultures. Data are normalized to control cultures and denote the mean \pm SEM of representative determinations made in three separate cultures. ${ }^{*} p<0.05$.

system, current results suggest that these protectants act through separate, possibly parallel pathways. This is in agreement with previous findings by Wishart et. al. (2008) [40] showing that $\mathrm{Wld}^{S}$ increases expression of cell cyclerelated genes through both $\mathrm{NAD}^{+}$-dependent and independent pathways. Thus, $\mathrm{NAD}^{+}$or its derivatives as well as $W l d^{S}$ and its targets protect dopamine processes and may aid in the development of therapeutics preserving the connections and circuitry important in PD.

The role of Nmnat and $\mathrm{NAD}^{+}$in recapitulating the full effect of $W l d^{S}$ has been controversial. In vitro studies have shown that overexpression of Nmnat1 by itself protects axons from many mechanical, genetic or toxininduced injuries [20,41]. In contrast, transgenic animals expressing nuclear Nmnat1 did not replicate the effects of $\mathrm{Wld}^{S}[42,43]$ whereas cytoplasmically [39] or axonally targeted Nmnat1 [34] were equally if not more effective. Thus, site of action plays a role in Nmnatl's effectiveness [20]. These data together with findings showing that the first $16 \mathrm{~N}$-terminal amino acids of the $W l d^{S}$ gene product are required for full $\mathrm{Wld}^{S}$ protection [26], possibly by redistributing enough $\mathrm{Wld}^{S}$ to cytoplasmic or axonal compartments, are consistent with the notion that both the N-terminal portion of $W l d^{S}$ and Nmnat1 are necessary for full axonal protection [20]. 


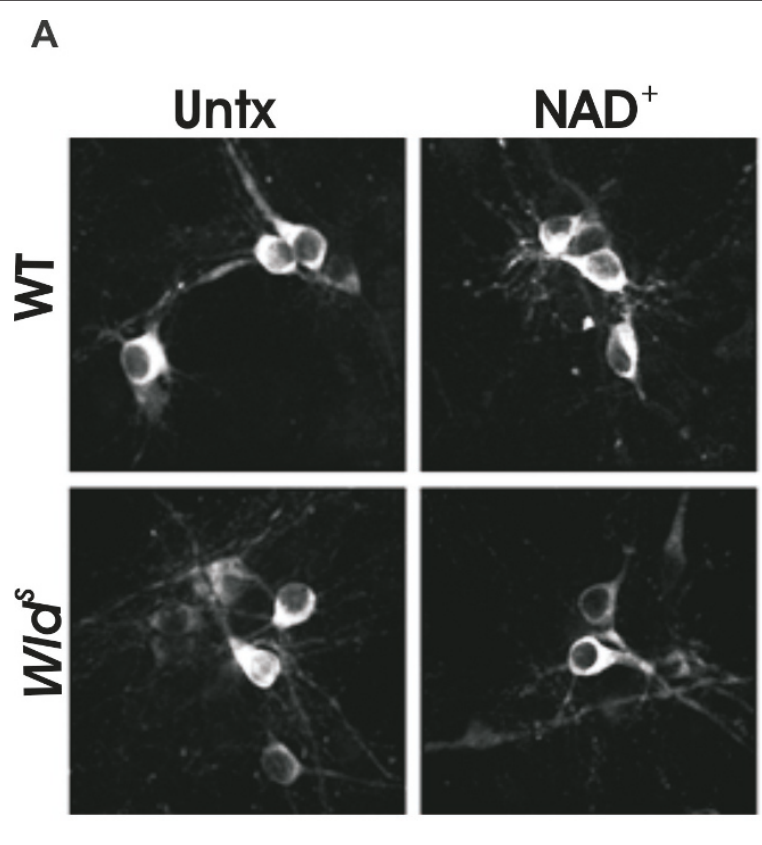

B

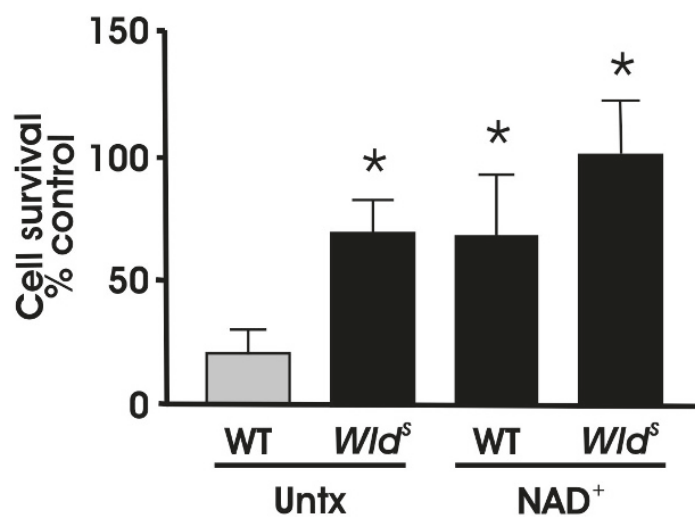

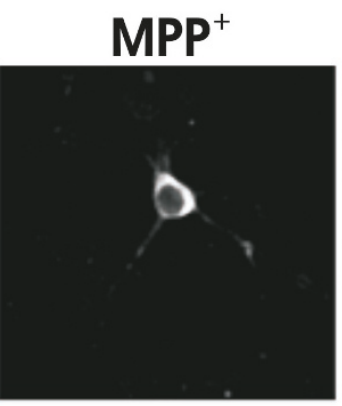

$\mathrm{NAD}^{+} / \mathrm{MPP}^{+}$

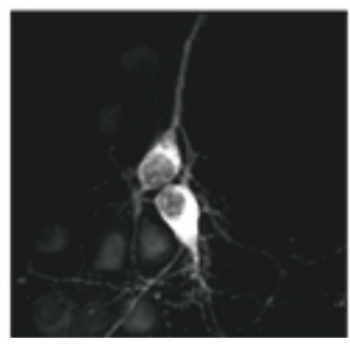

C
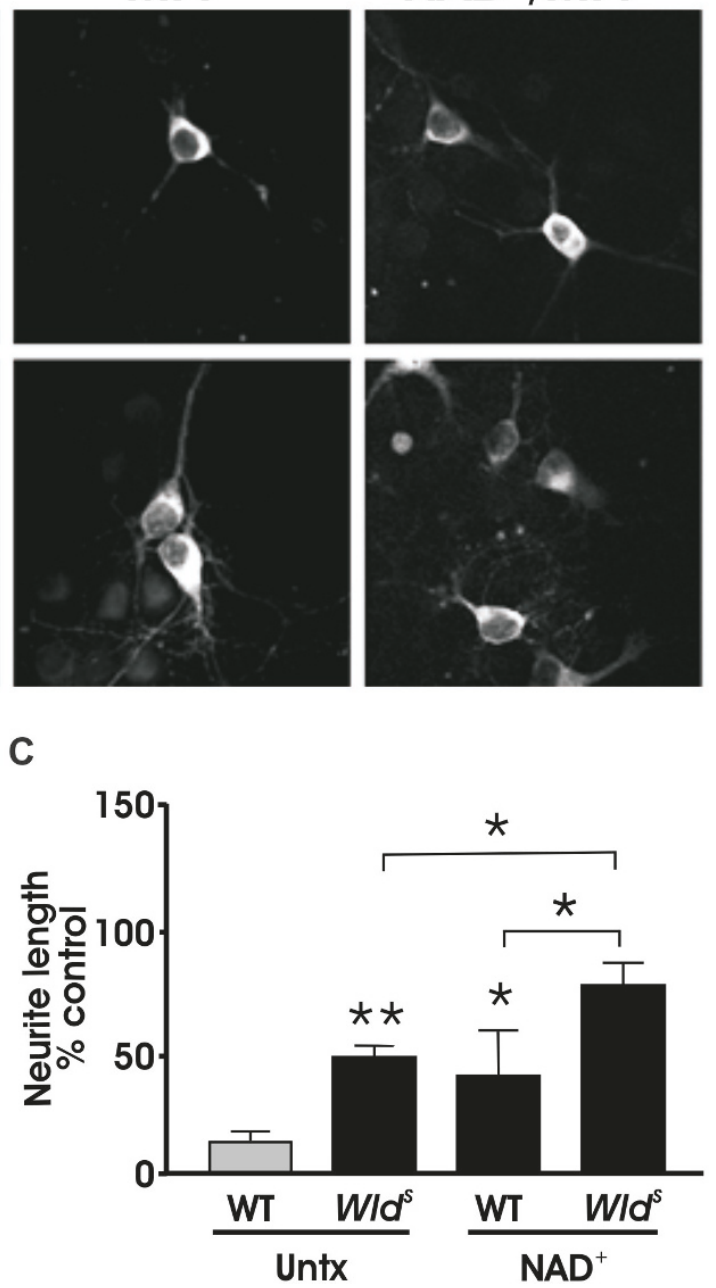

C

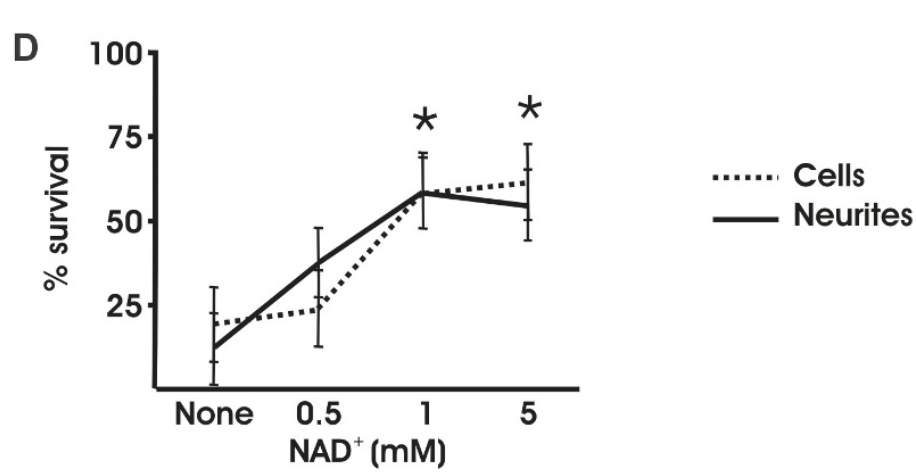

Figure 8 The protective effect of $\mathrm{NAD}^{+}$and $W I d^{S}$ are additive. (A) Dissociated midbrain cultures from both WT and WId $d^{S}$ mice were pretreated with $\mathrm{NAD}^{+} 24$ hours before addition of $2 \mu \mathrm{m} \mathrm{MPP}{ }^{+}$. (B) Quantification of TH+ cell bodies and (C) TH+ neurites show that NAD pretreatment was more effective in protecting $W I d^{s}$ neurites from $\mathrm{MPP}^{+}$versus untreated $W I d^{5}$ cultures. (D) NAD dose response curve showing that the protection seen with $1 \mathrm{mM} \mathrm{NAD}{ }^{+}$is maximal. Addition of $10 \mathrm{mM} \mathrm{NAD}^{+}$before $\mathrm{MPP}^{+}$treatment induced $50 \%$ cell death in

dopaminergic neurons (data not shown). Data are normalized to control cultures and denote the mean \pm SEM of representative determinations made in three separate cultures. ${ }^{*} p<0.05 ;{ }^{* *} p<0.001$. 
The importance of Nmnat catalytic activity is reflected in several mutational studies in which Nmnat's active sites have been disrupted and neuroprotection was lost $[26,27,29,43]$. Moreover, $\mathrm{NAD}^{+}$itself and/or some of its biosynthetic precursors, protect against axonal degeneration in peripheral model systems as well as in experimental autoimmune encephalomyelitis (EAE); [28,44], ischemia [45,46], Alzheimer's disease [47], and PD [48-50]. In at least one study however, addition of NAD ${ }^{+}$was not effective [42]. Moreover, Drosophila Nmnat (dNmnat) did not require enzymatic activity for axon protection against insults such as excitotoxicity, polyglutamine-induced dysfunction, or mechanical injury [32] leading to the suggestion that $\mathrm{dNmnat}$ may perform a chaperone-like function [30]. Indeed, structural studies of various Nmnats have revealed characteristic similarities to known chaperones such as UspA and Hsp100 [51]. Consistent with this notion, dNmnat was recently shown to function as a stress protein in response to heat shock, hypoxia, and the mitochondrial Complex I toxin, paraquat [52]. However, in dopaminergic neurons, Nmnat1 does not seem to function as either an axonal protectant or a chaperone.

Studies have indicated that $\mathrm{MPP}^{+}$can block electron transport by acting at the same site as the Complex I inhibitor, rotenone, leading to the production of free radical species and a loss of ATP production [53-55]. $\mathrm{MPP}^{+}$affects other processes as well including the rapid release of dopamine from vesicular stores [56,57]; depolymerization of microtubules [16,58]; induction of autophagy $[19,59]$, and the rapid loss of mitochondrial membrane potential and reduction in mitochondrial motility in dopamine axons [19]. Since many of these effects involve mitochondrial function, conceivably the $W l d^{S}$ gene product is involved in preserving mitochondrial health or maintaining homeostatic control. Recently, Barrientos et al. reported that $W l d^{S}$ is able to regulate the mitochondrial permeability transition pore (PTP) preventing, amongst other things, calcium release, ATP loss, oxidative stress and release of proteins involved in axonal degeneration [60]. This is consistent with Wishart et al. (2007) showing that synaptosomes isolated from $\mathrm{Wld}^{S}$ versus wild type animals expressed higher levels of various mitochondrial proteins including the PTP protein, VDAC2 [61]. Barrientos et al. suggested that $W l d^{S}$ is part of a regulatory cascade that also involves JNK activation upstream of PTP opening [60]. Although JNK is a known regulator of axon degeneration in DRGs [62], it has been reported to not play a role in 6-OHDA-mediated degeneration of the striatum [7]. In addition, we have recently showed that the JNK inhibitor, SP600125, did not prevent $\mathrm{MPP}^{+}$effects on dopaminergic mitochondria [19]. Thus diverse, unknown, regulatory steps appear to mediate $W l d^{S}$ effects in dopamine axons.
Given its role as a ubiquitous cofactor, $\mathrm{NAD}^{+}$influences many cellular decisions such as DNA damage repair [63] and transcriptional regulation and differentiation [64]. Earlier studies suggested that increased NAD ${ }^{+}$ levels led to SIRT activation which, in turn, activated a transcription factor that induced genes involved in neuroprotection [27,32]. Although an attractive hypothesis, subsequent studies using SIRT1 knock out animals did not support this notion for DRG neurons [65], or as in the present study, for dopaminergic neurons (Figure 8).

Unlike what we have reported in vivo [23], dopaminergic cell death from $\mathrm{MPP}^{+}$treatment was also attenuated in $W l d^{S}$ cultures (Figure 1). Given that $W l d^{S}$ is known to protect axons and synapses from injury, it is possible that it can also indirectly protect cell bodies. Similar indirect effects on cell bodies have been reported by Gillingwater et. al. (2004) in both the caudate nucleus and hippocampus of $\mathrm{Wld}^{S}$ mice following transient global ischemia [66]. More recently, a cytoplasm-targeted Nmnat transgenic mouse protected cell bodies and processes from NMDA-mediated excitotoxicity [37]. Authors of the latter study speculate that Nmnat can potentially influence a common pathway, albeit one not tied to caspase 3 activation, in certain neurons. Perhaps a similar pathway is activated in other systems as well since $W l d^{S}$ also protects motoneuron cell bodies in a mouse model of progressive motor neuropathy [67].

Why are results in dopamine neurons different than other systems? Because many of the studies published have been performed in peripheral model systems with dramatically over-expressed protein, there may be neuronal-specific or expression level-related effects that might account for the differences. For example, $W l d^{S}$ has shown protection in several central nervous system models, but few have been further tested with only Nmnat1 even in dissociated neuronal models [37]. Then too, dopaminergic axons may have intrinsic differences that contribute to the $W l d^{S}$ effect. For instance, dopamine neurons have fewer [68], smaller and slower mitochondria than non-dopaminergic neurons [19]. Moreover, dopamine neurons produce a neurotransmitter prone to oxidation [69], exhibit a greater dependence on L-type $\mathrm{Ca}^{2+}$ channels with subunits that result in deleterious amounts of intracellular calcium and ensuing mitochondrial dysfunction [70], and extend long, thin lightly-myelinated processes which are selectively vulnerable in PD [71]. This suggests that dopaminergic neurons may be more vulnerable to insults that affect mitochondrial function. Given that enzymatically inactive $W l d^{S}$ is able to protect dopaminergic, but not DRG neurons, it is possible that $W l d^{S}$ also protects mitochondria in a manner independent of its $\mathrm{NAD}^{+}$-synthesizing ability. This as yet unknown function of $\mathrm{Wld}^{S}$ may be unmasked in dopaminergic neurons due to their unique 
phenotype. In contrast, $\mathrm{NAD}^{+}$may contribute more to $W l d^{S}$-mediated protection in non-DA neurons.

\section{Conclusions}

In support of our previous in vivo study showing that $W l d^{S}$ protects dopaminergic terminal fields from MPTP, the current results demonstrate in dissociated dopamine cultures that the entire $W l d^{S}$ sequence is needed for axonal protection, regardless of its $\mathrm{NAD}^{+}$-synthesizing activity. Indeed, $\mathrm{NAD}^{+}$and $W l d^{S}$ act through separate, possibly parallel, mechanisms to protect dopamine axons. As $\mathrm{MPP}^{+}$is thought to impair mitochondrial function, in agreement with other studies, our results suggest that $W l d^{S}$ might be involved in preserving mitochondrial health or maintaining cellular metabolism. Given that Parkinson's disease is the second most common neurodegenerative disorder, our findings support the idea that studies expanding therapeutic efforts towards maintaining connections as well as saving the cell body will help in developing better interventions for PD.

\section{Materials and methods}

\section{Cell culture and toxin treatment}

For primary midbrain cultures, the ventral mesencephalon was removed from embryonic day 14 (E14) murine embryos as previously described [33,72]. Wild-type (C57/Bl6) and $\mathrm{Wld}^{S}$ (C57Bl/OlaHsd-WldS) mice were ordered from Harlan (Bichester, UK). Sirt1 knockout mice were obtained from Dr. Christian Sheline (Louisiana State University - Health Science Center, New Orleans, LA). Cyto Wld ${ }^{S}$ mice were obtained from Dr. Michael Coleman (Babraham Institute, UK) [73]. Animals were treated in accordance with the National Institutes of Health Guide for the Care and Use of Laboratory Animals. All procedures were approved by the Washington University School of Medicine animal experimentation committee. Plates were pre-coated overnight with $0.2 \mathrm{mg} / \mathrm{ml}$ poly-D-lysine (Sigma-Aldrich, St. Louis, MO). Cells were plated at a density of approximately $125,000 \mathrm{cells} / \mathrm{cm}^{2}$ and maintained in serum-free Neurobasal medium (Invitrogen, Carlsbad, CA) supplemented with $1 \times$ B27 supplement (Invitrogen), $0.5 \mathrm{mM}$ L-glutamine (Sigma-Aldrich), and $0.01 \mu \mathrm{g} /$ $\mathrm{ml}$ streptomycin plus $100 \mathrm{U}$ penicillin. Half of the culture medium was replaced with fresh Neurobasal medium after 5 days in vitro (DIV). Cultures were pretreated with $1 \mathrm{mM} \mathrm{NAD}^{+}, 1 \mathrm{mM} \mathrm{NMN}, 1 \mathrm{mM}$ nicotinic acid mononucleotide (NaMN), or a comparable volume of vehicle 24 hours before toxin treatment. Cultures were treated with either $1 \mu \mathrm{M}$ 1-methyl-4-phenylpyridinium (MPP+), the active metabolite of MPTP or vehicle on DIV 7. Dorsal root ganglion (DRG) cells were obtained from E14 murine embryos as previously described [74].
Cells were plated on coverslips precoated with $0.1 \mathrm{mg} /$ $\mathrm{ml}$ poly-L-ornithine (Invitrogen) and $32 \mu \mathrm{g} / \mathrm{ml}$ laminin1 (Invitrogen) and maintained in DRG media which consisted of Eagle Minimal Essential Media (Invitrogen) supplemented with chick embryo extract (Invitrogen), $10 \%$ fetal calf serum (Invitrogen), $50 \mathrm{ng} / \mathrm{ml}$ Nerve Growth Factor (Harlan Biosciences, Madison, WI) and $50 \mathrm{U} / \mathrm{ml}$ penicillin $-50 \mathrm{~g} / \mathrm{ml}$ streptomycin. Half of the culture medium was replaced with fresh DRG medium after DIV 5. After transduction with lentivirus on DIV 2 , DRG cultures were treated with $0.4 \mu \mathrm{M}$ vincristine or vehicle on DIV 7. $\mathrm{NAD}^{+}, \mathrm{NMN}, \mathrm{NaMN}, \mathrm{MPP}^{+}$, and vincristine were all obtained from Sigma-Aldrich.

\section{Lentiviral infection of dopaminergic neurons}

The lentiviral expression plasmids FUGW, FCIV-Wld $\mathrm{S}$, FCIV-Nmnat1, FCIV-Ube4b, FCIV-Nmnat3, FCIVNmnat1(W170A), FCIV-cytNmnat1, and FCIV-Wld ${ }^{S}$ (W258A) were obtained from Dr. Jeffrey Milbrandt (Washington University, Saint Louis). Lentiviruses expressing transgenes were generated by the Hope Center for Neurological Disorders Viral Core (Washington University, Saint Louis). For infection of DRG and primary midbrain neurons, $50 \mu \mathrm{l}$ lentivirus $\left(10^{5}\right.$ infectious units $/ \mu \mathrm{l}$ ) was added to the well of a $7-\mathrm{mm}$ dish containing approximately 70,000 neurons on DIV 2 . Transduced primary midbrain and DRG neurons were treated with $\mathrm{MPP}^{+}$and vincristine, respectively, on DIV 7. Viral infection and transgene expression was monitored using the GFP reporter via fluorescent microscopy.

\section{Immunocytochemistry}

Primary dopaminergic cultures and DRGs were plated in $7 \mathrm{~mm}$ microwell plates (MatTek Corp., Ashland, MA). Cells treated with $\mathrm{MPP}^{+}$were fixed with $4 \%$ paraformaldehyde (PFA) in PBS after 48 hours. Cultures were stained with sheep polyclonal anti-tyrosine hydroxylase (TH) (Novus Biologicals, Littleton, CO) and Cy3 $\alpha-$ sheep (Molecular Probes, Carlsbad, CA). Localization of cytoplasmic $W l d^{S}$ was confirmed using rabbit $W l d^{S}$ antibody (gift of M.P. Coleman) and Alexa488 $\alpha$-rabbit (Molecular Probes). $\mathrm{TH}^{+}$cells and neurites were counted using unbiased stereological methods (Stereo Investigator, MicroBrightField, Williston, VT). DRG cultures treated with vincristine were subsequently stained with mouse acetylated tubulin (Sigma-Aldrich) and Cy3 $\alpha$-mouse (Molecular Probes). Neurites were counted as described above. All images were acquired by confocal microscopy (Olympus Fluoview 500, Olympus, Center Valley, PA) and processed in ImageJ (NIH).

\section{Western Blotting}

Primary midbrain cultures were plated in 48-well plates and transduced with the transgene of interest as 
described above. Lysates were collected in RIPA buffer (150 mM NaCl, 1\% Nonidet P-40, 0.5\% NaDoc, 0.1\% SDS, $50 \mathrm{mM}$ Tris $\mathrm{pH}$ 8.0) with protease inhibitor mixture (Roche, Mannheim, Germany) and incubated on ice for 30 minutes. Insoluble cell debris was removed by centrifugation and the protein concentration of each cell lysate was determined by Bradford protein assay (BioRad, Hercules, CA). Equal amounts of protein were run on SDS-polyacrylamide gels and transferred to polyvinylidene diflouride (PVDF) membranes (BioRad). PVDF membranes were probed with either rabbit $\mathrm{Wld}^{S}$ antibody or chicken polyclonal anti-GFP antibody (Aves Labs, Tigard, OR). As a control, PVDF membranes were also probed with goat polyclonal anti-HRP60 antibody (Santa Cruz Biotechnology, Santa Cruz, CA). The secondary antibodies used were either a HRP-linked rabbit antibody or HRP-linked anti-chicken antibody and a HRP-linked anti-goat antibody (Jackson Immunoresearch, West Grove, PA). Membranes were developed with enhanced chemiluminescence (Amersham Biosciences), imaged with either a Storm PhosphorImager (Molecular Dynamics) or a ChemiDoc XRS System (BioRad, Hercules, CA) and band intensities were determined using ImageQuant software (Amersham Biosciences).

\section{Quantification of Cells and Neurites}

$\mathrm{TH}^{+}$cells and neurites were counted using unbiased stereological methods [75] (Stereo Investigator (MicroBrightfield, Williston, VT), in combination with a Zeiss Axioplan2 microscope (Thornwood, NY) and an Optronics Microfire camera. The number of counting sites necessary to achieve a coefficient of error $<0.1$ was determined by preliminary experiments. The total number of $\mathrm{TH}^{+}$cell bodies was calculated using the Fractionator function on Stereo Investigator by dividing the estimated number of cells by the estimated volume $\left(\mu \mathrm{m}^{3}\right)$ of the dish sampled. Using the Petrimetrics function on Stereo Investigator, $\mathrm{TH}^{+}$neurites intersecting the boundary of the Petrimetric probe were counted. Neurite length was derived by dividing the total estimated neurite length $(\mu \mathrm{m})$ by the estimated volume $\left(\mu \mathrm{m}^{3}\right)$ of the dish sampled

\section{Statistical analysis}

GraphPad Prism software (San Diego, CA) was used for statistical analysis. All data was collected from a minimum of three independent experiments done in triplicate. The significance of effects between control and experimental conditions was determined by a Student ttest or one-way ANOVA with Bonferroni Multiple Comparisons tests.

\section{Additional material}

Additional file 1: Figure S1 - Transduction efficiency of $W / d^{S}$, Nmnat1 and Ube4b lentiviruses. (A) Diagram of constructs used to transduce WT dissociated dopaminergic neurons. (B) Western blot of cell lysates from transduced primary midbrain cultures using the quantitative chemidoc imaging system with MAP2 as a loading control. Transduced constructs exhibited similar levels of expression. (C) Diagram of Nmnat1, inactive Nmnat1, cyto Nmnat1 and Nmnat3 lentiviral constructs used to transduce WT dissociated dopaminergic neurons. (D) Quantification of the western blots illustrates that these transgenes exhibit similar levels of expression. (E) Quantification of the western blots from the primary midbrain culture lysates of either WT mice, native $W / d^{5}$ mice, of WT mice transduced with WId $d^{S}$ virus. (E) Quantification of the western blots of brain lysates taken from either the substantia nigra (SN) or striatum (STR) of WT, native $W I d^{S}$ mice, or Cyto $W / d^{S}$ mice.

\section{Acknowledgements}

This work was supported by National Institutes of Health Grants NS39084 (K. L.O.) and National Institutes of Health Neuroscience Blueprint Core Grant NS057105 to Washington University. This work was also supported by the Bakewell Family Foundation. We thank Steven K. Harmon for technical support and Drs. Michael Coleman, Jeffrey Milbrandt, Christian Sheline, Valeria Cavalli and Jeong Sook Kim-Han for materials and helpful discussions.

\section{Authors' contributions}

JAD participated in experimental design, carried out all the experiments described and drafted the manuscript. KOM was involved in the design of experiments and production of the manuscript. Both authors participated in revising and editing the final manuscript. The final manuscript was read and approved by both authors.

\section{Competing interests}

The authors declare that they have no competing interests.

Received: 10 August 2011 Accepted: 8 February 2012

Published: 8 February 2012

\section{References}

1. Dauer W, Przedborski S: Parkinson's disease: mechanisms and models. Neuron 2003, 39:889-909.

2. Blum D, Torch S, Lambeng N, Nissou M, Benabid AL, Sadoul R, Verna JM: Molecular pathways involved in the neurotoxicity of 6-OHDA, dopamine and MPTP: contribution to the apoptotic theory in Parkinson's disease. Prog Neurobiol 2001, 65:135-172.

3. Braak H, Ghebremedhin E, Rub U, Bratzke H, Del Tredici K: Stages in the development of Parkinson's disease-related pathology. Cell Tissue Res 2004, 318:121-134

4. Bernheimer $H$, Birkmayer $W$, Hornykiewicz $O$, Jellinger $K$, Seitelberger F: Brain dopamine and the syndromes of Parkinson and Huntington. Clinical, morphological and neurochemical correlations. J Neurol Sci 1973, 20:415-455.

5. Scherman D, Desnos C, Darchen F, Pollak P, Javoy-Agid F, Agid Y: Striatal dopamine deficiency in Parkinson's disease: role of aging. Ann Neurol 1989, 26:551-557.

6. Riederer P, Wuketich S: Time course of nigrostriatal degeneration in parkinson's disease. A detailed study of influential factors in human brain amine analysis. J Neural Transm 1976, 38:277-301.

7. Cheng HC, Ulane CM, Burke RE: Clinical progression in Parkinson disease and the neurobiology of axons. Ann Neurol 2010, 67:715-725.

8. Fearnley JM, Lees AJ: Ageing and Parkinson's disease: substantia nigra regional selectivity. Brain 1991, 114(Pt 5):2283-2301.

9. Kramer ML, Schulz-Schaeffer WJ: Presynaptic alpha-synuclein aggregates, not Lewy bodies, cause neurodegeneration in dementia with Lewy bodies. J Neurosci 2007, 27:1405-1410.

10. Saha AR, Hill J, Utton MA, Asuni AA, Ackerley S, Grierson AJ, Miller CC, Davies AM, Buchman VL, Anderton BH, Hanger DP: Parkinson's disease 
alpha-synuclein mutations exhibit defective axonal transport in cultured neurons. J Cell Sci 2004, 117:1017-1024

11. Li Y, Liu W, Oo TF, Wang L, Tang Y, Jackson-Lewis V, Zhou C, Geghman K, Bogdanov M, Przedborski S, Beal MF, Burke RE, Li C: Mutant LRRK2 (R1441G) BAC transgenic mice recapitulate cardinal features of Parkinson's disease. Nat Neurosci 2009, 12:826-828.

12. Kitada T, Asakawa S, Hattori N, Matsumine H, Yamamura Y, Minoshima S, Yokochi M, Mizuno Y, Shimizu N: Mutations in the parkin gene cause autosomal recessive juvenile parkinsonism. Nature 1998, 392:605-608.

13. Weihofen A, Thomas KJ, Ostaszewski BL, Cookson MR, Selkoe DJ: Pink1 forms a multiprotein complex with Miro and Milton, linking Pink1 function to mitochondrial trafficking. Biochemistry 2009, 48:2045-2052.

14. Mortiboys H, Thomas KJ, Koopman WJ, Klaffke S, Abou-Sleiman P, Olpin S, Wood NW, Willems PH, Smeitink JA, Cookson MR, Bandmann O: Mitochondrial function and morphology are impaired in parkin-mutant fibroblasts. Ann Neurol 2008, 64:555-565.

15. Ren $Y$, Liu W, Jiang H, Jiang $Q$, Feng J: Selective vulnerability of dopaminergic neurons to microtubule depolymerization. J Biol Chem 2005, 280:34105-34112.

16. Cappelletti G, Pedrotti B, Maggioni MG, Maci R: Microtubule assembly is directly affected by MPP(+)in vitro. Cell Biol Int 2001, 25:981-984

17. Cartelli D, Ronchi C, Maggioni MG, Rodighiero S, Giavini E, Cappelletti G: Microtubule dysfunction precedes transport impairment and mitochondria damage in MPP+ -induced neurodegeneration. $J$ Neurochem 2010, 115:247-258.

18. Morfini G, Pigino G, Opalach K, Serulle Y, Moreira JE, Sugimori M, Llinas RR, Brady ST: 1-Methyl-4-phenylpyridinium affects fast axonal transport by activation of caspase and protein kinase C. Proc Natl Acad Sci USA 2007, 104:2442-2447.

19. Kim-Han JS, Antenor-Dorsey JA, O'Malley KL: The Parkinsonian Mimetic, MPP+, Specifically Impairs Mitochondrial Transport in Dopamine Axons. J Neurosci 2011, 31:7212-7221.

20. Coleman MP, Freeman MR: Wallerian degeneration, wld(s), and nmnat. Annu Rev Neurosci 2010, 33:245-267.

21. Mi W, Beirowski B, Gillingwater TH, Adalbert R, Wagner D, Grumme D, Osaka H, Conforti L, Arnhold S, Addicks K, Wada K, Ribchester RR, Coleman MP: The slow Wallerian degeneration gene, WIdS, inhibits axonal spheroid pathology in gracile axonal dystrophy mice. Brain 2005, 128:405-416.

22. Sajadi A, Schneider BL, Aebischer P: WIds-mediated protection of dopaminergic fibers in an animal model of Parkinson disease. Curr Biol 2004, 14:326-330.

23. Hasbani DM, O'Malley $\mathrm{KL}$ : WId(S) mice are protected against the Parkinsonian mimetic MPTP. Exp Neurol 2006, 202:93-99.

24. Mack TG, Reiner M, Beirowski B, Mi W, Emanuelli M, Wagner D, Thomson D, Gillingwater T, Court F, Conforti L, Fernando FS, Tarlton A, Andressen C, Addicks K, Magni G, Ribchester RR, Perry VH, Coleman MP: Wallerian degeneration of injured axons and synapses is delayed by a Ube4b/ Nmnat chimeric gene. Nat Neurosci 2001, 4:1199-1206.

25. Coleman MP, Conforti L, Buckmaster EA, Tarlton A, Ewing RM, Brown MC, Lyon MF, Perry VH: An 85-kb tandem triplication in the slow Wallerian degeneration (WIds) mouse. Proc Natl Acad Sci USA 1998, 95:9985-9990.

26. Conforti L, Wilbrey A, Morreale G, Janeckova L, Beirowski B, Adalbert R, Mazzola F, Di Stefano M, Hartley R, Babetto E, Smith T, Gilley J, Billington RA, Genazzani AA, Ribchester RR, Magni G, Coleman M: Wld S protein requires Nmnat activity and a short $\mathrm{N}$-terminal sequence to protect axons in mice. J Cell Biol 2009, 184:491-500.

27. Araki T, Sasaki Y, Milbrandt J: Increased nuclear NAD biosynthesis and SIRT1 activation prevent axonal degeneration. Science 2004, 305:1010-1013.

28. Sasaki Y, Araki T, Milbrandt J: Stimulation of nicotinamide adenine dinucleotide biosynthetic pathways delays axonal degeneration after axotomy. J Neurosci 2006, 26:8484-8491.

29. Avery MA, Sheehan AE, Kerr KS, Wang J, Freeman MR: WIdS requires Nmnat1 enzymatic activity and N16-VCP interactions to suppress Wallerian degeneration. J Cell Biol 2009, 184:501-513.

30. Zhai RG, Zhang F, Hiesinger PR, Cao Y, Haueter CM, Bellen HJ: NAD synthase NMNAT acts as a chaperone to protect against neurodegeneration. Nature 2008, 452:887-891.

31. Wen Y, Parrish JZ, He R, Zhai RG, Kim MD: Nmnat exerts neuroprotective effects in dendrites and axons. Mol Cell Neurosci 2011.
32. Zhai RG, Cao Y, Hiesinger PR, Zhou Y, Mehta SQ, Schulze KL, Verstreken P, Bellen HJ: Drosophila NMNAT maintains neural integrity independent of its NAD synthesis activity. PLOS Biol 2006, 4:e416.

33. Lotharius J, Dugan LL, O'Malley KL: Distinct mechanisms underlie neurotoxin-mediated cell death in cultured dopaminergic neurons. J Neurosci 1999, 19:1284-1293.

34. Babetto E, Beirowski B, Janeckova L, Brown R, Gilley J, Thomson D, Ribchester RR, Coleman MP: Targeting NMNAT1 to axons and synapses transforms its neuroprotective potency in vivo. J Neurosci 2010, 30:13291-13304.

35. Sasaki Y, Milbrandt J: Axonal degeneration is blocked by nicotinamide mononucleotide adenylyltransferase (Nmnat) protein transduction into transected axons. J Biol Chem 2010, 285:41211-41215.

36. Press C, Milbrandt J: Nmnat delays axonal degeneration caused by mitochondrial and oxidative stress. J Neurosci 2008, 28:4861-4871.

37. Verghese PB, Sasaki Y, Yang D, Stewart F, Sabar F, Finn MB, Wroge CM, Mennerick S, Neil JJ, Milbrandt J, Holtzman DM: Nicotinamide mononucleotide adenylyl transferase 1 protects against acute neurodegeneration in developing CNS by inhibiting excitotoxic-necrotic cell death. Proc Natl Acad Sci USA 2011, 108:19054-19059.

38. Sasaki Y, Vohra BP, Lund FE, Milbrandt J: Nicotinamide mononucleotide adenylyl transferase-mediated axonal protection requires enzymatic activity but not increased levels of neuronal nicotinamide adenine dinucleotide. J Neurosci 2009, 29:5525-5535

39. Sasaki Y, Vohra BP, Baloh RH, Milbrandt J: Transgenic mice expressing the Nmnat1 protein manifest robust delay in axonal degeneration in vivo. Neurosci 2009, 29:6526-6534.

40. Wishart TM, Pemberton HN, James SR, McCabe CJ, Gillingwater TH: Modified cell cycle status in a mouse model of altered neuronal vulnerability (slow Wallerian degeneration; WIds). Genome Biol 2008, 9 R101.

41. Yan T, Feng Y, Zheng J, Ge X, Zhang Y, Wu D, Zhao J, Zhai Q: Nmnat2 delays axon degeneration in superior cervical ganglia dependent on its NAD synthesis activity. Neurochem Int 2010, 56:101-106.

42. Conforti L, Fang G, Beirowski B, Wang MS, Sorci L, Asress S, Adalbert R, Silva A, Bridge K, Huang XP, Magni G, Glass JD, Coleman MP: NAD(+) and axon degeneration revisited: Nmnat1 cannot substitute for WId(S) to delay Wallerian degeneration. Cell Death Differ 2007, 14:116-127.

43. Yahata N, Yuasa S, Araki T: Nicotinamide mononucleotide adenyly|transferase expression in mitochondrial matrix delays Wallerian degeneration. J Neurosci 2009, 29:6276-6284.

44. Kaneko S, Wang J, Kaneko M, Yiu G, Hurrell JM, Chitnis T, Khoury SJ, He Z: Protecting axonal degeneration by increasing nicotinamide adenine dinucleotide levels in experimental autoimmune encephalomyelitis models. J Neurosci 2006, 26:9794-9804.

45. Yang J, Klaidman LK, Chang ML, Kem S, Sugawara T, Chan P, Adams JD: Nicotinamide therapy protects against both necrosis and apoptosis in a stroke model. Pharmacol Biochem Behav 2002, 73:901-910.

46. Sakakibara Y, Mitha AP, Ayoub IA, Ogilvy CS, Maynard KI: Delayed treatment with nicotinamide (vitamin B3) reduces the infarct volume following focal cerebral ischemia in spontaneously hypertensive rats, diabetic and non-diabetic Fischer 344 rats. Brain Res 2002, 931:68-73.

47. Demarin V, Podobnik SS, Storga-Tomic D, Kay G: Treatment of Alzheimer's disease with stabilized oral nicotinamide adenine dinucleotide: a randomized, double-blind study. Drugs Exp Clin Res 2004, 30:27-33.

48. Birkmayer JG, Vrecko C, Volc D, Birkmayer W: Nicotinamide adenine dinucleotide (NADH)-a new therapeutic approach to Parkinson's disease. Comparison of oral and parenteral application. Acta Neurol Scand Supp/ 1993, 146:32-35.

49. Birkmayer JG: Coenzyme nicotinamide adenine dinucleotide: new therapeutic approach for improving dementia of the Alzheimer type. Ann Clin Lab Sci 1996, 26:1-9.

50. Kuhn W, Muller T, Winkel R, Danielczik S, Gerstner A, Hacker R, Mattern C, Przuntek H: Parenteral application of NADH in Parkinson's disease: clinical improvement partially due to stimulation of endogenous levodopa biosynthesis. J Neural Transm 1996, 103:1187-1193.

51. Zhai RG, Rizzi M, Garavaglia S: Nicotinamide/nicotinic acid mononucleotide adenylyltransferase, new insights into an ancient enzyme. Cell Mol Life Sci 2009, 66:2805-2818.

52. Ali YO, McCormack R, Darr A, Zhai RG: Nicotinamide Mononucleotide Adenylyltransferase Is a Stress Response Protein Regulated by the Heat 
Shock Factor/Hypoxia-inducible Factor 1a Pathway. J Biol Chem 2011, 286:19089-19099.

53. Nicklas WJ, Vyas I, Heikkila RE: Inhibition of NADH-linked oxidation in brain mitochondria by 1-methyl-4-phenyl-pyridine, a metabolite of the neurotoxin, 1-methyl-4-phenyl-1,2,5,6-tetrahydropyridine. Life Sci 1985, 36:2503-2508.

54. Ramsay RR, Krueger MJ, Youngster SK, Gluck MR, Casida JE, Singer TP: Interaction of 1-methyl-4-phenylpyridinium ion (MPP+) and its analogs with the rotenone/piericidin binding site of NADH dehydrogenase. $J$ Neurochem 1991, 56:1184-1190.

55. Ramsay RR, Salach Jl, Singer TP: Uptake of the neurotoxin 1-methyl-4phenylpyridine $(\mathrm{MPP}+)$ by mitochondria and its relation to the inhibition of the mitochondrial oxidation of NAD+-linked substrates by MPP+. Biochem Biophys Res Commun 1986, 134:743-748.

56. Lotharius J, O'Malley KL: The parkinsonism-inducing drug 1-methyl-4phenylpyridinium triggers intracellular dopamine oxidation. A novel mechanism of toxicity. J Biol Chem 2000, 275:38581-38588.

57. Chang GD, Ramirez VD: The mechanism of action of MPTP and MPP+ on endogenous dopamine release from the rat corpus striatum superfused in vitro. Brain Res 1986, 368:134-140.

58. Cappelletti G, Surrey T, Maci R: The parkinsonism producing neurotoxin MPP+ affects microtubule dynamics by acting as a destabilising factor. FEBS Lett 2005, 579:4781-4786.

59. Zhu JH, Horbinski C, Guo F, Watkins S, Uchiyama Y, Chu CT: Regulation of autophagy by extracellular signal-regulated protein kinases during 1methyl-4-phenylpyridinium-induced cell death. Am J Pathol 2007, 170:75-86.

60. Barrientos SA, Martinez NW, Yoo S, Jara JS, Zamorano S, Hetz C, Twiss JL, Alvarez J, Court FA: Axonal degeneration is mediated by the mitochondrial permeability transition pore. J Neurosci 2011, 31:966-978.

61. Wishart TM, Paterson JM, Short DM, Meredith S, Robertson KA, Sutherland C, Cousin MA, Dutia MB, Gillingwater TH: Differential proteomics analysis of synaptic proteins identifies potential cellular targets and protein mediators of synaptic neuroprotection conferred by the slow Wallerian degeneration (WIds) gene. Mol Cell Proteomics 2007, 6:1318-1330.

62. Miller BR, Press C, Daniels RW, Sasaki Y, Milbrandt J, DiAntonio A: A dual leucine kinase-dependent axon self-destruction program promotes Wallerian degeneration. Nat Neurosci 2009, 12:387-389.

63. Surjana D, Halliday GM, Damian DL: Role of nicotinamide in DNA damage, mutagenesis, and DNA repair. J Nucleic Acids 20102010.

64. Hisahara S, Chiba S, Matsumoto H, Horio Y: Transcriptional regulation of neuronal genes and its effect on neural functions: NAD-dependent histone deacetylase SIRT1 (Sir2a). J Pharmacol Sci 2005, 98:200-204.

65. Wang J, Zhai Q, Chen Y, Lin E, Gu W, McBurney MW, He Z: A local mechanism mediates NAD-dependent protection of axon degeneration. J Cell Biol 2005, 170:349-355.

66. Gillingwater TH, Haley JE, Ribchester RR, Horsburgh K: Neuroprotection after transient global cerebral ischemia in WId(s) mutant mice. J Cereb Blood Flow Metab 2004, 24:62-66.

67. Ferri A, Sanes JR, Coleman MP, Cunningham JM, Kato AC: Inhibiting axon degeneration and synapse loss attenuates apoptosis and disease progression in a mouse model of motoneuron disease. Curr Biol 2003, 13:669-673.

68. Liang CL, Wang TT, Luby-Phelps K, German DC: Mitochondria mass is low in mouse substantia nigra dopamine neurons: implications for Parkinson's disease. Exp Neurol 2007, 203:370-380.

69. Hastings TG: The role of dopamine oxidation in mitochondrial dysfunction: implications for Parkinson's disease. J Bioenerg Biomembr 2009, 41:469-472.

70. Surmeier DJ, Guzman JN, Sanchez-Padilla J, Goldberg JA: What causes the death of dopaminergic neurons in Parkinson's disease? Prog Brain Res 2010, 183:59-77.

71. Dickson DW, Fujishiro H, Orr C, DelleDonne A, Josephs KA, Frigerio R, Burnett M, Parisi JE, Klos KJ, Ahlskog JE: Neuropathology of non-motor features of Parkinson disease. Parkinsonism Relat Disord 2009, 15(Suppl 3): S1-5.

72. Bernstein Al, Garrison SP, Zambetti GP, O'Malley KL: 6-OHDA generated ROS induces DNA damage and p53- and PUMA-dependent cell death. Mol Neurodegener 2011, 6:2.
73. Beirowski B, Babetto E, Gilley J, Mazzola F, Conforti L, Janeckova L, Magni G, Ribchester RR, Coleman MP: Non-nuclear WId(S) determines its neuroprotective efficacy for axons and synapses in vivo. J Neurosci 2009, 29:653-668.

74. Brown JA, Wysolmerski RB, Bridgman PC: Dorsal root ganglion neurons react to semaphorin $3 \mathrm{~A}$ application through a biphasic response that requires multiple myosin II isoforms. Mol Biol Cell 2009, 20:1167-1179.

75. Magni G, Amici A, Emanuelli M, Orsomando G, Raffaelli N, Ruggieri S: Enzymology of NAD+ homeostasis in man. Cell Mol Life Sci 2004, 61:19-34.

doi:10.1186/1750-1326-7-5

Cite this article as: Antenor-Dorsey and O'Malley: WId ${ }^{5}$ but not Nmnat1 protects dopaminergic neurites from $\mathrm{MPP}^{+}$neurotoxicity. Molecular Neurodegeneration 2012 7:5.

\section{Submit your next manuscript to BioMed Central and take full advantage of:}

- Convenient online submission

- Thorough peer review

- No space constraints or color figure charges

- Immediate publication on acceptance

- Inclusion in PubMed, CAS, Scopus and Google Scholar

- Research which is freely available for redistribution

Submit your manuscript at www.biomedcentral.com/submit
Biomed Central 